九州大学学術情報リポジトリ

Kyushu University Institutional Repository

\title{
Transport Performance Simulation of Separating System for Self-propelled Peanut Harvester using EDEM Software
}

Lim, Je

Department of Bio-Industrial Machinery Engineering, Chonbuk National University

Kim, Myoung-Ho

Department of Bio-Industrial Machinery Engineering, Chonbuk National University / Institute for Agricultural Machinery \& ICT Convergence, Chonbuk National University

Kim, Seong-Min

Department of Bio-Industrial Machinery Engineering, Chonbuk National University / Institute for Agricultural Machinery \& ICT Convergence, Chonbuk National University

Choe, Jung-Seob

Department of Precision Mechanical Engineering, Kyungpook National University

他

https://doi.org/10.5109/1686490

出版情報：九州大学大学院農学研究院紀要. 61 (2)，pp.361-365，2016-09-01. Faculty of Agriculture, Kyushu University

バージョン：

権利関係: 


\title{
Transport Performance Simulation of Separating System for Self-propelled Peanut Harvester using EDEM Software
}

\author{
Je LIM ${ }^{1}$, Myoung-Ho KIM ${ }^{1,3}$, Seong-Min KIM ${ }^{1,3}$, Jung-Seob CHOE ${ }^{2}$, Eiji INOUE, \\ Takashi OKAYASU and Dae-Cheol KIM. ${ }^{1,3, *}$
}

\author{
Department of Agro-environmental Science, Faculty of Agriculture, Kyushu University, \\ 6-10-1 Hakozaki Higashi-ku, Fukuoka 812-8581, Japan \\ (Received May 2, 2016 and accepted May 10, 2016)
}

\begin{abstract}
This study evaluated a DEM (Discrete Element Method) model through test results and analysis results for the simulation of the conveying performance of the separating system in a peanut harvester. With the validated DEM model, analysis under three conditions of slope angle of separating system compare with horizon $\left(-7^{\circ}, 0^{\circ}\right.$, and $\left.7^{\circ}\right)$ was also conducted to examine the conveying performance. From the comparison between the test results and simulation results, the conveying performances of $0^{\circ}$ and $7^{\circ}$ were observed to be the same at the initial period and completion period; however, the gradient of $0^{\circ}$ and $7^{\circ}$ from the simulation were higher than the ones from the test by $8.9 \%\left(0^{\circ}\right)$ and $9.2 \%\left(7^{\circ}\right)$. The higher gradient means that the transport performance is better. The gradient of $-7^{\circ}$ from the simulation was higher than the one from the test by $3.6 \%$, and the amount of the peanuts from the simulation was larger than the test by $500 \mathrm{~g}$ at the initial period of 5 seconds. The higher gradient of the simulation was due to the losses at the collecting part as $3.4 \%\left(0^{\circ}\right), 3.1 \%\left(7^{\circ}\right)$, and $2.0 \%\left(-7^{\circ}\right)$. The error in the amount of the peanuts $(500 \mathrm{~g})$ at the initial period of 5 seconds with $-7^{\circ}$ was due to the initial input difference between the test and simulation.
\end{abstract}

Key words: Peanut Harvester, Peanut, Shaking screen, EDEM, DEM (Discrete Element Method), Particle behavior analysis

\section{INTRODUCTION}

Agricultural mechanization for upland farming has been implemented in Korea and other countries; as a result, research and development of peanut harvesters, one of the machines for upland farming, have been conducted actively. Studies on peanut harvesters in Korea were started with research by Jun et al. (1998) and were continued to develop a tractor-mounted peanut harvester (Kim, 2008) and to evaluate the performance of the separating system in a peanut harvester (Kim, 2013).

Research on peanut harvesters in Korea has progressed under various tests but still has some problems adjusting to environments in Korea. Main problem is caused by the field located in sloping terrain. $79.6 \%$ of fields are located in the area having inclinations of $2 \sim$ $15 \%$, and $12.2 \%$ is in the area having inclinations of $15 \sim$ $30 \%$. $8.2 \%$ of field is in the flat area (Jo, 1999)

This study was conducted to develop peanut harvesters that were suitable for the sloping terrain. A previous study to examine the influence of inclination on the processing capacity found that higher inclination failed to convey the peanuts to the collecting part (Kim, 2013). Conveying performance of the separating system should be improved to solve this problem. However, manufac-

${ }^{1}$ Department of Bio-Industrial Machinery Engineering, Chonbuk National University, 567, Baekje-daero, Deokjin-gu, Jeonju-si, Jeollabuk-do, 54896, Republic of Korea

Department of Precision Mechanical Engineering, Kyungpook National University, Gajangdong, Sangju, Republic of Korea

Institute for Agricultural Machinery \& ICT Convergence, Chonbuk National University, 567, Baekje-daero, Deokjin-gu, Jeonju-si, Jeollabuk-do, 54896, Republic of Korea

* Corresponding Author (E-mail: dckim12@jbnu.ac.kr) turing machines and evaluating the performance for the improvement need lots of time and costs. Therefore, simulation-based prediction could be used to reduce these difficulties.

This study used particle behavior analysis software called EDEM based on DEM (Discrete Element Method) to examine the conveying performance. Material properties of the peanut were modeled by DE particles. The simulation results of the conveying performance were compared with the test data to evaluate the analysis model.

\section{MATERIALS AND METHODS}

\section{Self-propelled peanut harvester}

A self-propelled peanut harvester that has a rated engine speed of 2,600 rpm and a rated power of $44.13 \mathrm{~kW}$ was used for this study. The experiments were conducted in a stationary state, and the configuration (Figure 1)

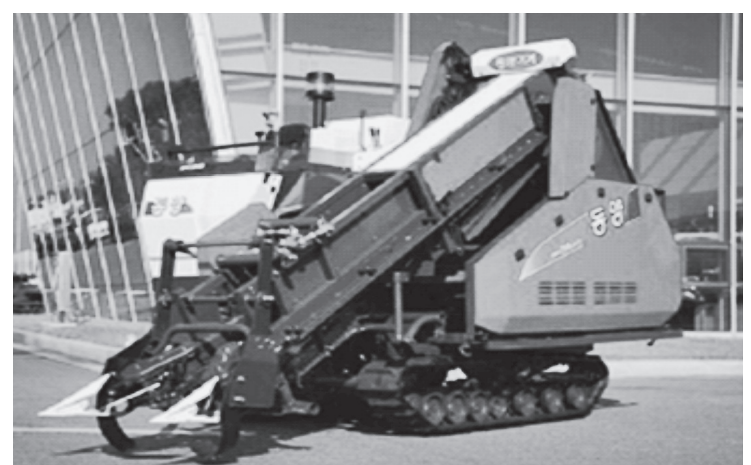

Fig. 1. Configuration of the self-propelled peanut harvester. 
Table 1. Specifications of the peanut harvester

\begin{tabular}{|c|c|c|c|}
\hline \multirow{5}{*}{ Drive system } & \multirow{3}{*}{ Dimensions } & Overall height & $4,600 \mathrm{~mm}$ \\
\hline & & Overall width & $1,835 \mathrm{~mm}$ \\
\hline & & Weight & $19,600 \mathrm{~N}$ \\
\hline & \multicolumn{2}{|c|}{ Standard working speed } & $0 \sim 0.77 \mathrm{~m} / \mathrm{s}$ \\
\hline & \multicolumn{2}{|c|}{ Power } & $44.13 \mathrm{~kW}$ \\
\hline \multirow{2}{*}{ Digging system } & \multicolumn{2}{|c|}{ Digging method / Depth } & Fixed type / $200 \mathrm{~mm}$ \\
\hline & \multicolumn{2}{|c|}{ Number of Planting rows / Width } & $2 / 600 \mathrm{~mm}$ \\
\hline Threshing system & \multicolumn{2}{|c|}{ Threshing method } & Hitting type \\
\hline Separating system & \multicolumn{2}{|c|}{ Separating method } & Pitching + Winnowing \\
\hline Collecting system & \multicolumn{2}{|c|}{ Collection method } & Burlap bag type \\
\hline
\end{tabular}

and specifications (Table 1) of the harvester are shown as follows.

\section{Separating system}

Mixtures of peanut pods with other foreign materials were conveyed to the shaking screen where dirt fell through, and the peanuts were conveyed to the collecting part. Mesh size of the shaking screen was $14 \times$ $120 \mathrm{~mm}^{2}$. The width of the whole screen was $610 \mathrm{~mm}$, and the length was $1,315 \mathrm{~mm}$. The shaking screen generated a swing by reciprocating motion of the eccentric cam shaft with 4-bar linkage. Figure 2 shows the shape of the shaking screen.

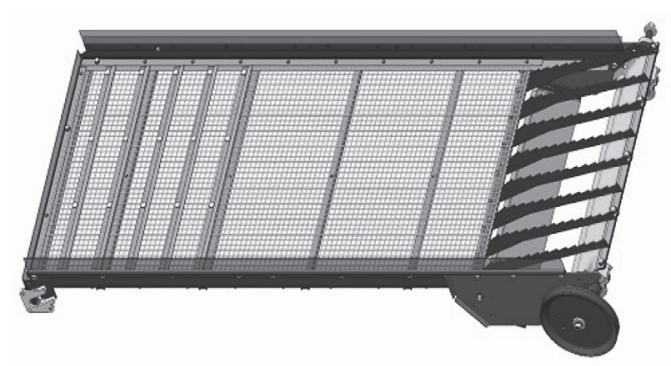

Fig. 2. 3D shape of shaking screen.

In order to evaluate the conveying performance of the separating system, the peanuts that passing through the collecting part should be collected directly every five seconds. To do this, collection boxes were installed on the conveyor belt after disconnecting power of the conveyor belt as shown in figure 3 , and the box was replaced every five seconds to collect the peanuts. Figure 4 represents the collecting plate in the peanut harvester.

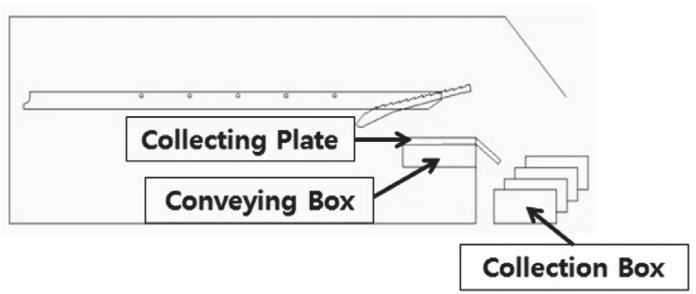

Fig. 3. Installation position of the collecting plate and collection box.

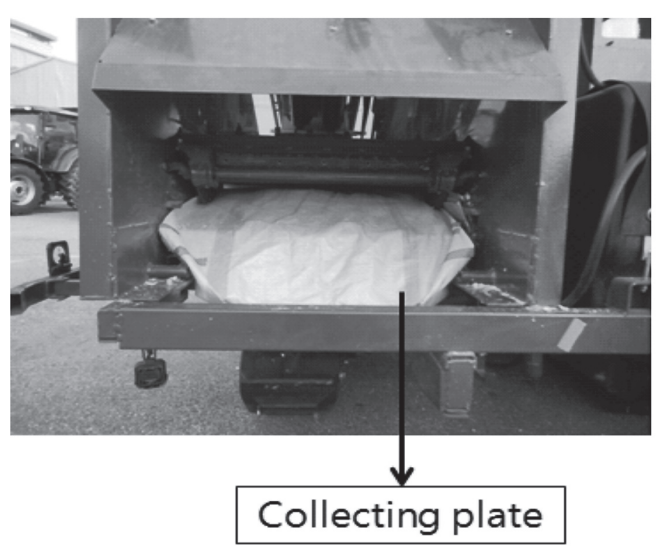

Fig. 4. Installation of the collecting plate in peanut harvester.

\section{Sample}

Kim (2013)'s experiment about the processing capacity determined the amount of the input peanut to the separating part as $5 \mathrm{~kg}$ at the working area of $5 \times 1 \mathrm{~m}^{2}$ and working speed of $0.3 \mathrm{~m} / \mathrm{s}$. This study adjusted Kim (2013)'s conditions as $10 \mathrm{~kg}$ after considering the target working speed of the peanut harvester $(0.45 \mathrm{~m} / \mathrm{s})$ and severe working condition such as oversupply. The simulation for the conveying performance was created with $10 \mathrm{~kg}$ peanuts for 20 seconds; therefore, same conditions (input of $10 \mathrm{~kg}$ peanuts for 20 seconds) were determined for the test. Cultivar of the peanut used in this study was Palpal, and the moisture content of the peanut was $6.41 \%$, which was measured after drying at $130^{\circ} \mathrm{C}$ for six hours following oven-dry method (ASAE STANDARDS, 2001).

\section{EDEM}

EDEM (EDEM Ver 2.7, DEM solutions, United Kingdom) was a simulation tool for arbitrary setting of the contact model between particle-particle and particlegeometry using DEM. This software could reduce costs and time for product development relating particle behavior, process design, and optimization by adjusting particle flow rate or generating particle at the precise position.

In this study, the process of EDEM analysis consists of three steps. First step is the modeling of the separating system and peanuts that were created by particles in EDEM software. Second step is setting of the contact 
model between peanut-peanut and peanut-steel. In this step, various material properties are necessary. Last step is the simulation and consideration of the result.

\section{Material property}

Accurate input of the material property is important because simulation results can be different depending on the material properties of the sample. Material properties needed for the particle behavior analysis were Poisson's Ratio, Shear Modulus, and density. Interrelation material properties between particle-particle and particle-geometry should also be input. Interrelation material properties includes the coefficient of restitution, the coefficient of static friction, and the coefficient of rolling friction. Table 2 presents the material properties used in EDEM.

In this study, the peanuts were created by particles. To create the particles of the peanuts, samples of the peanut were measured (length: $39 \mathrm{~mm}$ and thickness: $15 \mathrm{~mm}$ ). A peanut was created with five particles in EDEM. Figure 5 presents the shape and size of the particles used in EDEM.

Table 2. Material property input in EDEM

\begin{tabular}{cc}
\hline Material property & Interrelation material property \\
\hline Poisson's Ratio & Coefficient of restitution \\
Shear modulus & Coefficient of static friction \\
Density & Coefficient of rolling friction \\
\hline
\end{tabular}

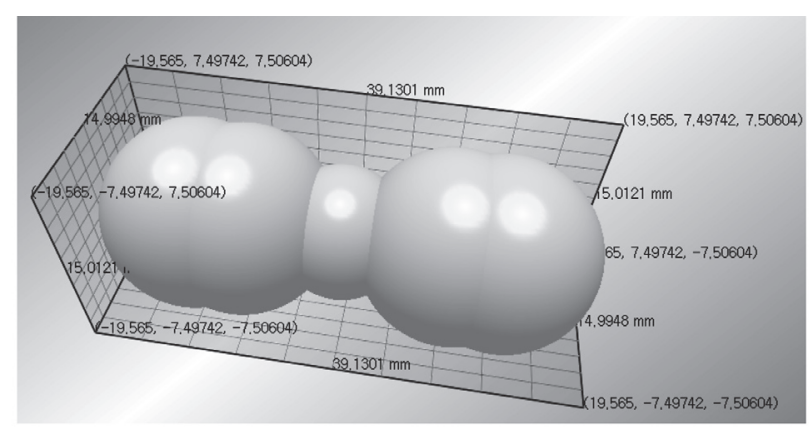

Fig. 5. Shape and size of particles.

\section{Method}

Experiments at a rotational speed $(370 \mathrm{rpm})$ of the shaking screen were conducted to examine the conveying performance depending on three levels of slope angle of separating system compare with horizon $\left(-7^{\circ}, 0^{\circ}\right.$, and $7^{\circ}$ ). All the experiments were repeated twice to enhance the reliability. $10 \mathrm{~kg}$ peanuts were transferred evenly for 20 seconds to the peanut harvester with three levels of slope $\left(-7^{\circ}, 0^{\circ}\right.$, and $\left.7^{\circ}\right)$, and each collection box was replaced every five seconds and measured the weight. The peanuts were input into the front of separating screen uniformly and collected in the collection box by step.

\section{Analysis of the experiment}

With the test results, the accumulated weight of the peanuts that were collected at the collection part every five seconds was created in a graph. Then, linear regression analysis was conducted in the actual period that performed conveying, and the conveying performance was examined depending on the slope angle.

Simulation results were also created in a graph, and the actual conveying period was examined with linear regression analysis.

\section{RESULTS AND DISCUSSION}

\section{Comparison between performance test and simu- lation}

Figure 6 presents the time-lapse images of the EDEM results under $0^{\circ}$ and $7^{\circ}$ slope angles. The remained peanuts are seen at the separating screen of $7^{\circ}$ slope angle after 30 seconds, due to the slow transport performance compare with $0^{\circ}$ slope angle. Figure 7 presents the comparison between test result and simulation result of the entire processing of $0^{\circ}$, and figure 8 shows the linear regression model of two results. The gradient of the simulation (0.4823) was larger than the one of the test (0.4392) by $8.9 \%$, and beginning and end showed a similar tendency as presented in figure 8 . The higher gradient means that the transport performance is better. Difference between the gradient of the test and simulation was caused by the peanut loss (3.4\%) during the processes of input and collecting.

Figure 9 presents the comparison between test result and simulation result of the entire processing of $7^{\circ}$, and figure 10 shows the linear regression model of two results. The gradient of the simulation (0.4308) was larger than the one of the test (0.3911) by $9.2 \%$, and beginning and end showed a similar tendency in figure 9 as in the results of $0^{\circ}$. Larger gradient of the simulation than the test was caused by the peanut loss (3.1\%) during the processes of input and collecting.

Figure 11 presents the comparison between test results and simulation of the entire processing of $-7^{\circ}$, and figure 12 shows the linear regression model of two results. The gradient of the simulation (0.4619) was larger than the one of the test $(0.4452)$ by $3.6 \%$, however, this gradient was not high as in the results of $0^{\circ}$ $(8.9 \%)$ and $7^{\circ}(9.2 \%)$. Difference between the gradient of test and simulation was caused by the peanut loss during the processes of input and collecting. The simulation showed higher value (500 g) than the test result during five seconds from the beginning, and this was due to the error of the simulation and test for the initial input.

\section{SUMMARY AND CONCLUSIONS}

This study evaluated a DEM model through test results and analysis results for the simulation of the conveying performance of the separating system in a peanut harvester. With the validated DEM model, analysis under various slope angle of separating system compare with horizon $\left(-7^{\circ}, 0^{\circ}\right.$, and $\left.7^{\circ}\right)$ was also conducted to estimate the conveying performance of the separating system. Results of this study are as follows: 


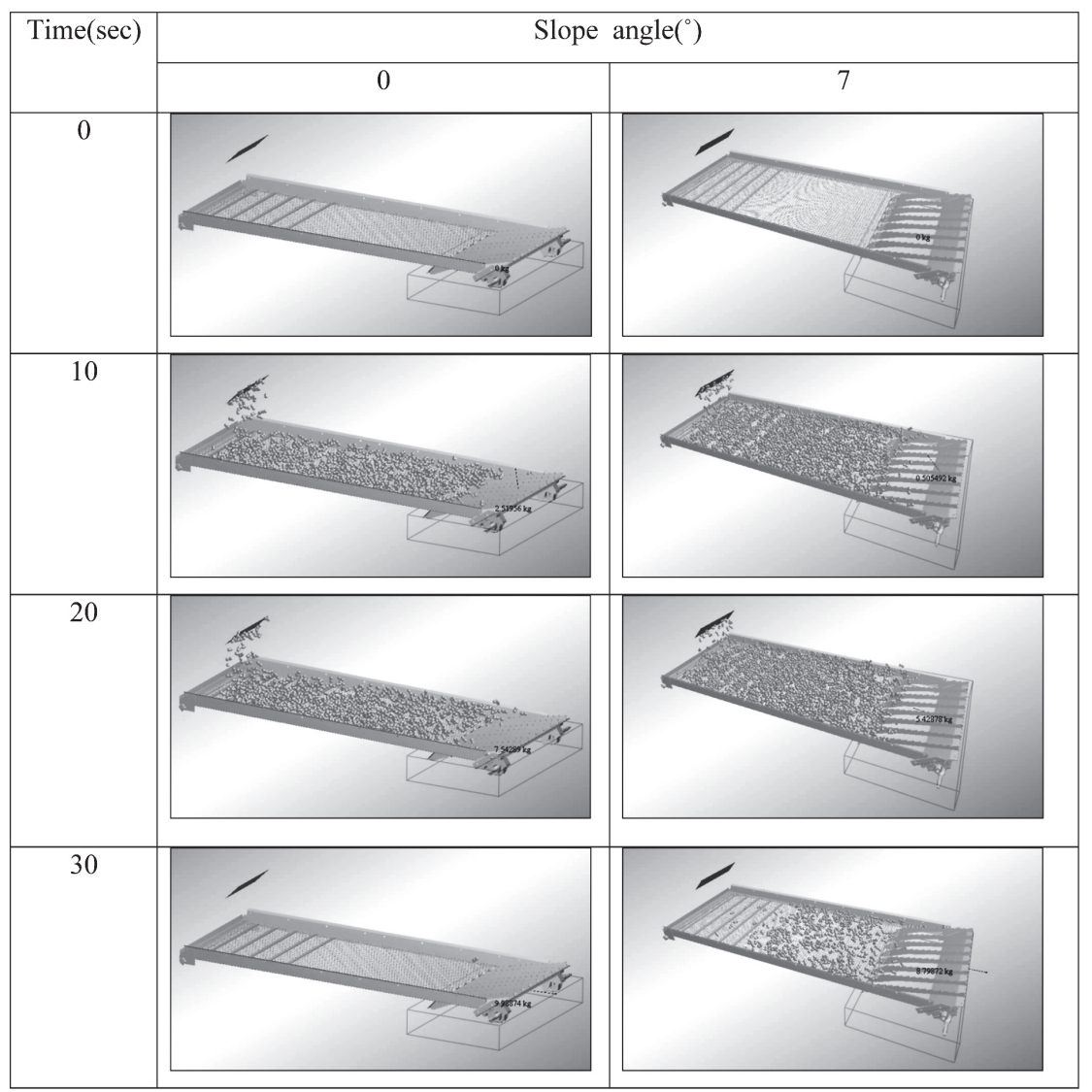

Fig. 6. The time-lapse images of the EDEM results under $0^{\circ}$ and $7^{\circ}$ slope angles.

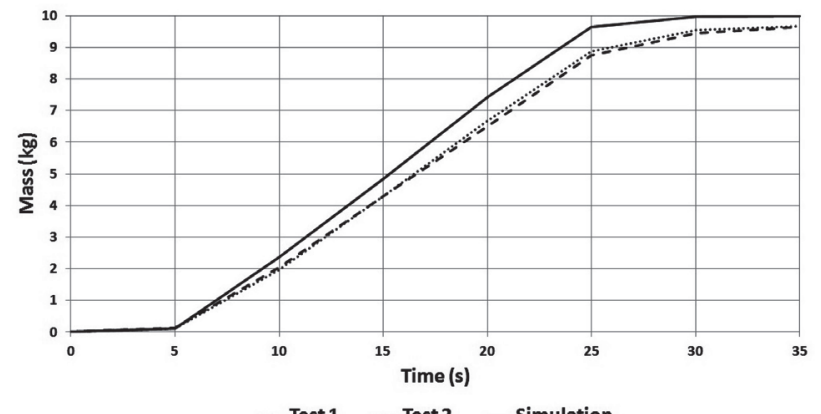

...... Test 1 - - Test 2 -Simulation

Fig. 7. Comparison between simulation and test results of the conveyed peanuts at 0 degree.

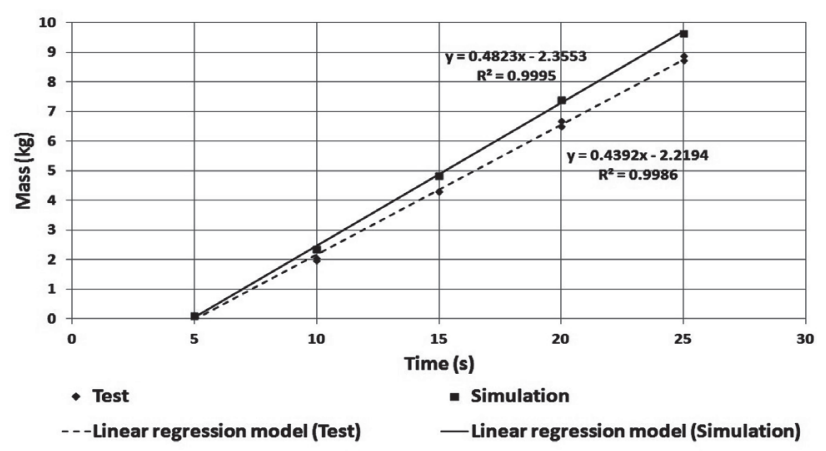

Fig. 8. Linear regression model of the steady-state from test and simulation results ( 0 degree).

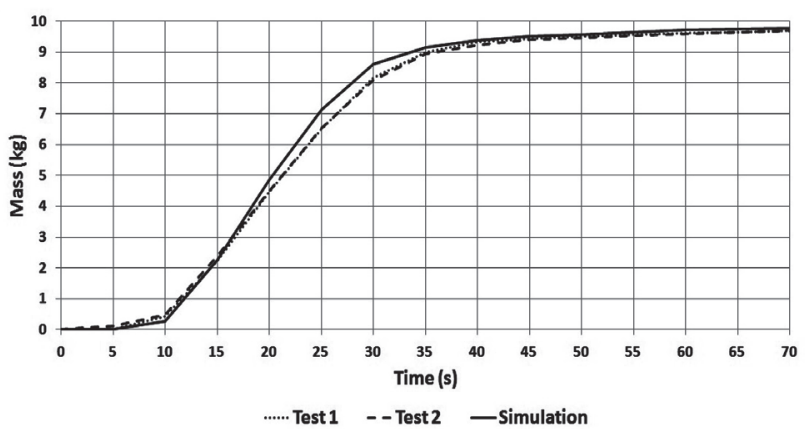

Fig. 9. Comparison between simulation and test results of the conveyed peanuts at 7 degree.

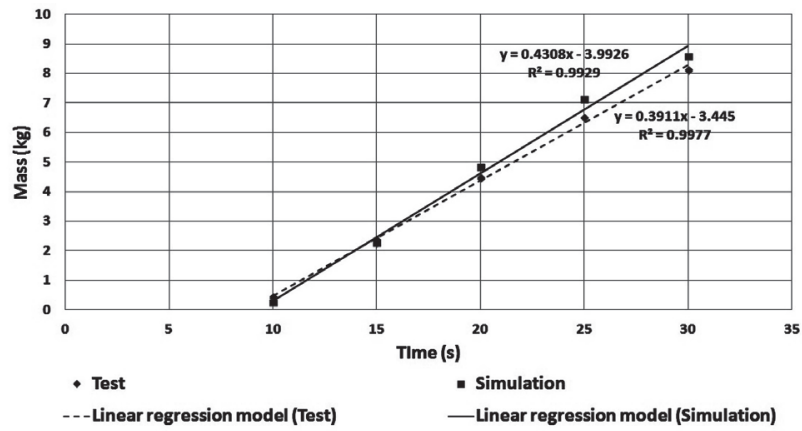

Fig. 10. Linear regression model of the steady-state from the test and simulation results ( 7 degree). 


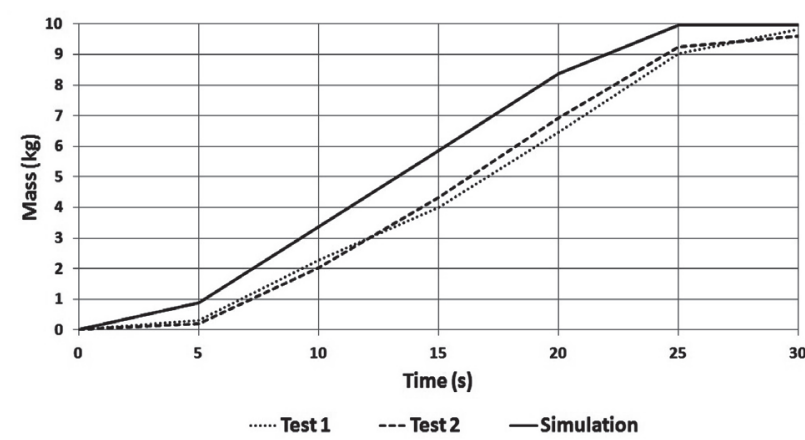

Fig. 11. Comparison between simulation and test results of the conveyed peanuts at $-7^{\circ}$.

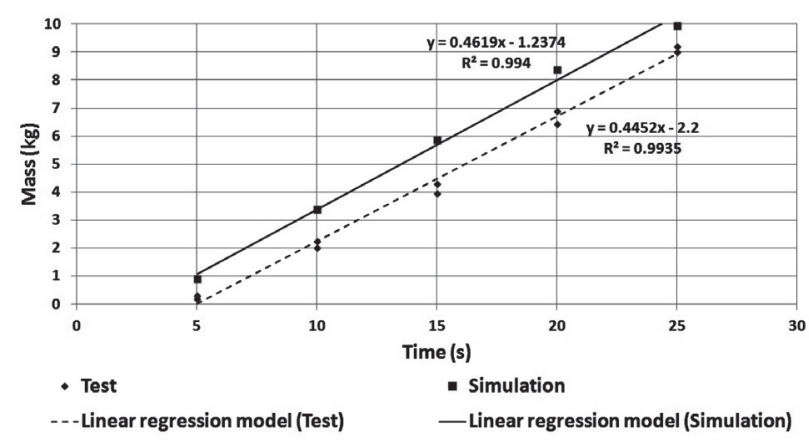

Fig. 12. Linear regression model of the steady-state from the test and simulation results ( -7 degree).

(1) From the comparison between the test results and simulation, the conveying performances of $0^{\circ}$ and $7^{\circ}$ were observed to be the same at the initial period and completion period; however, the gradient from the simulation were higher than the ones from the test by $8.9 \%$ $\left(0^{\circ}\right)$ and $9.2 \%\left(7^{\circ}\right)$. The higher gradient means that the transport performance is better. The gradient from the simulation of $-7^{\circ}$ was higher than the one from the test by $3.6 \%$, and the amount of the peanuts from the simulation was larger than the test by $500 \mathrm{~g}$ at the initial period of five seconds.

The higher gradient of the simulation was due to the losses at the collecting part by $3.4 \%\left(0^{\circ}\right), 3.1 \%\left(7^{\circ}\right)$, and $2.0 \%\left(-7^{\circ}\right)$. The error in the amount of the peanuts (500 g) at the initial period of five seconds with $-7^{\circ}$ was due to the initial input difference between the test and simulation.

(2) In order to improve the conveying performance, the slope angle of the separating part should be controlled automatically from the driver's seat or should be adjusted automatically depending on the inclination.

\section{ACKNOWLEDGEMENT}

This work was supported by Korea Institute of Planning and Evaluation for Technology in Food, Agriculture, Forestry and Fisheries(IPET) through Agriculture, Food and Rural Affairs Research Center Support Program, funded by Ministry of Agriculture, Food and Rural Affairs(MAFRA)(716001-7)

\section{REFERENCES}

ASAE STANDARDS. 2001. Moisture measurement - Peanuts : 588-589

Jo, Y. K. 1999. Detailed scrutiny of the field soil. RDA(Rural Development Administration of Korea). Agricultural Technology Information : 170-177

Jun, H. J., J. T. Hong, W. J. Park, Y. Choi, and S. W. Lee. 1998. Development of peanut harvester. Journal of the Korean Society for Agricultural Machinery 3(2): 20-24

Kim, M. H. 2008. Development of a tractor attached root-harvester for peanut. Department of Bio-Industrial Machinery Engineering Graduate School, Kyungpook university: 16-26

Kim, B. J. 2013. An experimental study for improving the separating performace of the peanut harvester sorting system. Master's thesis, Chonbuk National University, Korea 